\title{
PROGRESS IN AMS MEASUREMENTS AT THE LLNL SPECTROMETER
}

\author{
J. R. SOUTHON, J. S. VOGEL, S. E. TRUMBORE, J. C. DAVIS, M. L. ROBERTS \\ M. W. CAFFEE, R. C. FINKEL, I. D. PROCTOR, D. W. HEIKKINEN, A. J. BERNO and \\ R. S. HORNADY
}

Center for Accelerator Mass Spectrometry, University of California, Lawrence Livermore National Laboratory, Livermore, California 94550 USA

\begin{abstract}
We report on the present status of the Lawrence Livermore AMS spectrometer, including sample throughput and progress towards routine $1 \%$ measurement capability for ${ }^{14} \mathrm{C}$, first results on other isotopes and experience with a multisample high-intensity ion source.
\end{abstract}

\section{INTRODUCTION}

The AMS measurement program at LLNL began in earnest in late 1989, and has initially concentrated on ${ }^{14} \mathrm{C}$ measurements for biomedical and geoscience applications (Davis et al. 1990). We have now begun measurements on ${ }^{7} \mathrm{Be},{ }^{10} \mathrm{Be},{ }^{26} \mathrm{Al}$ and ${ }^{36} \mathrm{Cl}$, and are presently testing the spectrometer performance for ${ }^{3} \mathrm{H},{ }^{41} \mathrm{Ca}$ and ${ }^{129} \mathrm{I}$.

Our laboratory has a strong biomedical AMS program of ${ }^{14} \mathrm{C}$ tracer measurements involving large numbers of samples (sometimes hundreds in a single experiment) at ${ }^{14} \mathrm{C}$ concentrations typically 0.5 to 5 times modern, but occasionally highly enriched. The sample preparation techniques required for high throughput and low cross-contamination for this work are discussed elsewhere (Vogel 1992). Similar demands are placed on the AMS measurement system, and in particular, on the ion source. Modifications to our GIC 846 ion source, described below, allow us to run biomedical and geoscience or archaeological samples in the same source wheel with no adverse effects. The source has a capacity for 60 samples ( 45 unknowns) in a single wheel and provides currents of 50-80 $\mu \mathrm{A}$ of $\mathrm{C}^{-}$from hydrogen-reduced graphite (Vogel, Nelson \& Southon 1987). These currents and sample capacity provide high throughput for both biomedical and other measurements: the AMS system can be started up, tuned, and a wheel of carbon samples measured to $1-1.5 \%$ in less than a day; and two biomedical wheels can be measured per day without difficulty.

\section{${ }^{14}$ C PRECISION AND ACCURACY}

We are currently attempting to achieve a routine $1 \%$ measurement capability for ${ }^{14} \mathrm{C}$. Figures 1 and 2 show data from recent tests of measurement precision and accuracy, using repeated measurements to $1 \%$ statistics on graphite samples prepared from Oxalic Acid I and II and ANU sugar. Two of the Ox-I samples were used as standards, and the mean of these was used for normalization of the isotope ratios from the remaining "unknowns." The results for the unknowns were then converted to percent modern (pMC) data. The cumulative measurement accuracy for each unknown was taken to be the fractional deviation of the mean result after $\mathrm{N}$ measurements from the correct $\mathrm{pMC}$ value for that standard.

Some samples showed the precision expected from the counting statistics, but others had far greater scatter, indicating that other sources of variation were present. In addition, the trends in accuracy did not follow the precision: 5 or 6 measurements were sufficient for precisions of $1 \%$, but a far larger number was needed for $1 \%$ accuracy. The results show systematic differences of 0.5 to $1 \%$ between samples, and that some of the accuracy problems arose because the samples used for normalization gave ratios that were slightly high. The tests also showed that deviations between 


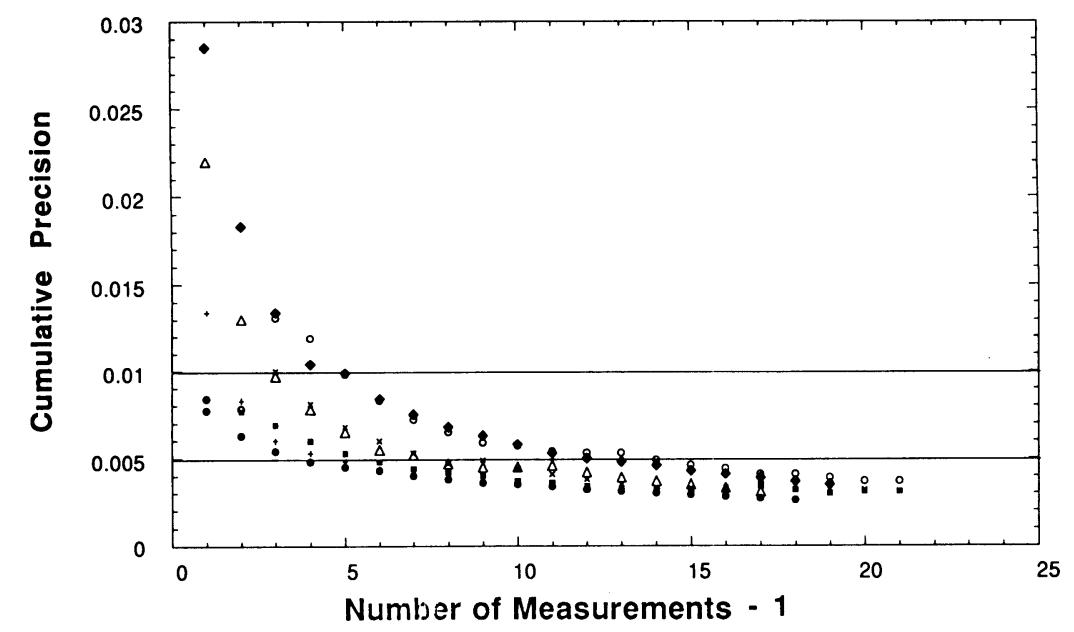

Fig. 1. ${ }^{14} \mathrm{C}$ measurement precision $v s$. number of measurements for repeated measurements on seven "unknowns," April 1991 (see text). The vertical axis gives the cumulative fractional precision at one sigma of the mean result for each sample, and the horizontal axis is the number of individual measurements minus one. The single-measurement precision expected from the $1 \%$ counting statistics for the unknowns and each of two normalizing standards is $1.2 \%$.

separate aliquots of the same graphite were similar to those between different graphites; and there were no obvious systematic differences with sample size, $\mathrm{C}^{-}$output, or the depth of packing of the sample into the holder.

While these studies were in progress, several spectrometer problems that could have affected measurement performance were uncovered. These included accelerator tube damage resulting from an $\mathrm{SF}_{6}$ leak and from a damaged entrance grid, use of a set of damaged stripper foils, and drift in the ion source extraction power supply. In addition, a planned reconstruction of the AMS injection line to better match the ion source to the injection magnet had not yet taken place. In retrospect, we could hardly have picked a worse time to carry out such tests, and the results probably give a fair indication of worst-case performance!

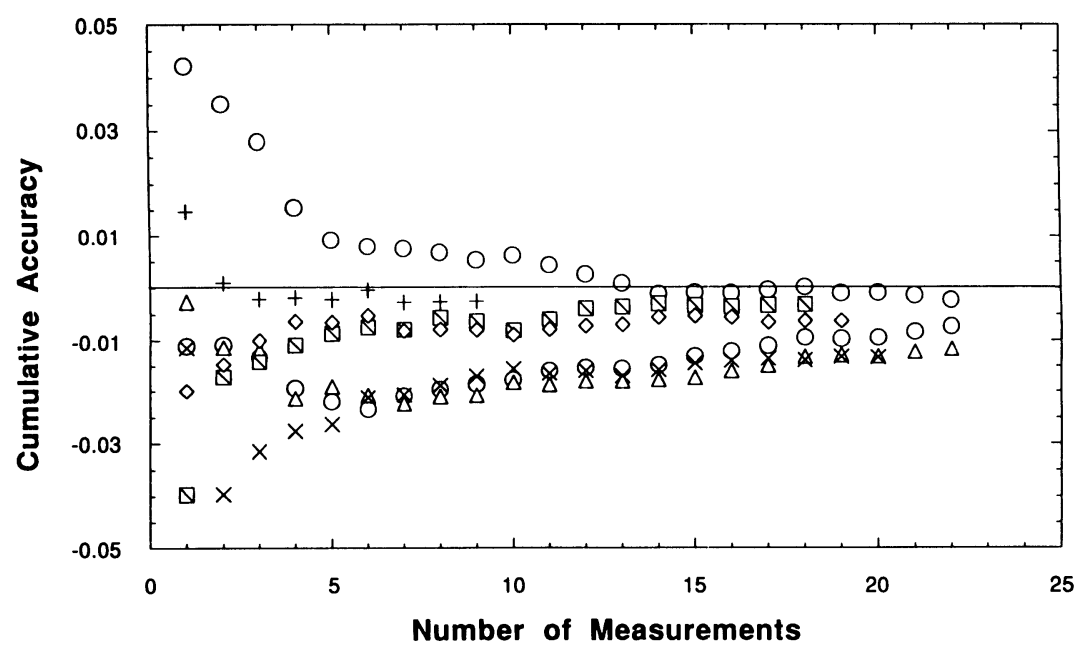

Fig. 2. Measurement accuracy for the samples shown in Figure 1 (see text) 
Measurements taken during a routine run in May, when most of the problems had been corrected, were more encouraging. Table 1 shows results for eight different ANU sugar samples. The scatter in the results for two of the samples (nos. 4 and 30) are higher than expected given the $1 \%$ statistics of the individual measurements, but the data do suggest that accuracies and precisions close to $1 \%$ can be achieved with a reasonable number of measurements per sample.

TABLE 1. Precision and Accuracy for ANU Sugar Samples May 1991

\begin{tabular}{cccccc}
\hline $\begin{array}{c}\text { Sample } \\
\text { no. }\end{array}$ & $\begin{array}{c}\text { No. of } \\
\text { runs }\end{array}$ & $\begin{array}{c}\text { Mean sample } \\
{ }^{14} \mathrm{C}^{13} \mathrm{C} \text { ratio } \mathrm{R}^{*}\end{array}$ & $\mathrm{SD}^{* *}$ & $\mathrm{R} / \mathrm{R}_{\mathrm{m}}$ & $\mathrm{SD}$ \\
\hline 3 & 4 & .24454 & .00135 & 0.9971 & 0.0055 \\
4 & 3 & .24377 & .00368 & 0.9939 & 0.0150 \\
6 & 4 & .24630 & .00076 & 1.0044 & 0.0031 \\
7 & 4 & .24506 & .00124 & 0.9992 & 0.0051 \\
29 & 5 & .24628 & .00145 & 1.0042 & 0.0059 \\
30 & 5 & .24899 & .00214 & 1.0152 & 0.0087 \\
31 & 5 & .24261 & .00110 & 0.9892 & 0.0045 \\
32 & 4 & .24359 & .00108 & 0.9932 & 0.0044 \\
\hline \multicolumn{7}{l}{ Global mean ratio $\left(\mathrm{R}_{\mathrm{m}}\right) .24536$} \\
\hline
\end{tabular}

*Units: ${ }^{14} \mathrm{C}$ counts per nanoCoulomb of ${ }^{13} \mathrm{C}$

**Standard error in the mean (from the distribution of results from individual runs)

\section{${ }^{10}$ Be Results}

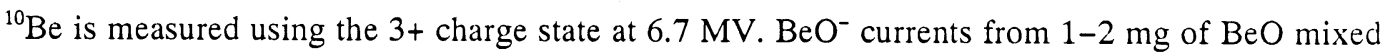
with $\mathrm{Ag}$ binder range from 0.5 to $4 \mu \mathrm{A}$. Thirty percent of the beam is transmitted to the $3+$ charge state, with ${ }^{10} \mathrm{Be}$ count rates of $3 \mathrm{~s}^{-1}$ from samples having ${ }^{10} \mathrm{Be} /{ }^{\beta} \mathrm{Be}$ ratios around $10^{-12}$. Curiously, the beam transmission does not increase when carbon foil strippers are augmented with traces of stripper gas to suppress the "Coulomb explosion" from BeO breakup; the large acceptance of our high energy spectrometer may be sufficient to handle even the increased beam emittance from the unsuppressed breakup.

An attempt to use the front portion of our multi-anode ionization detector as a gaseous absorber for ${ }^{10} \mathrm{~B}$ (Fifield et al. 1990) failed for reasons that remain unclear. High-boron samples showed reduced pulse heights from the rear (active) anodes, even though the voltages on the various detector electrodes were unaffected. We therefore currently use an $11 \mathrm{mg} \mathrm{cm}^{-2}$ Havar window to stop ${ }^{10} \mathrm{~B}$, and detect ${ }^{10} \mathrm{Be}$ using the first two anodes. Backgrounds of $5 \times 10^{-15}$ and $1.5 \times 10^{-14}$ were obtained from beryl and from commercial $\mathrm{BeO}$ (Aldrich), respectively, and tests on a suite of known standards showed accuracies/precisions of 2 to $3 \%$. Measurements on meteorite samples and seawater are underway, and investigations of the applicability of ${ }^{10} \mathrm{Be}$ in dating soil profiles are beginning.

\section{${ }^{36} \mathrm{Cl}$ Results}

Our ${ }^{36} \mathrm{Cl}$ measurements are carried out on $\mathrm{Cl}^{7+}$ at a terminal voltage of $7.8 \mathrm{MV}$. The ion source produces $20-40 \mu \mathrm{A}$ of $\mathrm{Cl}^{-}$from $10 \mathrm{mg}$ of AgCl, and transmission to the $7+$ charge state is about $15 \%$, leading to count rates of around $80 \mathrm{~s}^{-1}$ for samples with ${ }^{36} \mathrm{Cl} / \mathrm{Cl}$ around $1 \times 10^{-12}$. We presently accelerate ${ }^{36} \mathrm{Cl}$ and ${ }^{37} \mathrm{Cl}$, and pulse the ${ }^{37} \mathrm{Cl}$ through the accelerator unattenuated, relying on a short pulse length of $1 \mathrm{~ms}$ to avoid significant accelerator loading. 
The spectra in our 4-anode gas ionization detector contain only ${ }^{36} \mathrm{Cl}$ and ${ }^{36} \mathrm{~S}$, and the background under the ${ }^{36} \mathrm{Cl}$ peak arises from events where ${ }^{36} \mathrm{~S}$ ions scatter off detector gas nuclei. Our attempts to achieve low ${ }^{36} \mathrm{~S}$ rates from Ta holders were variable and sometimes spectacularly unsuccessful. Our best results have been from samples packed in $\mathrm{AgBr}$, with ${ }^{36} \mathrm{~S}$ rates of 500 to 1000 counts s${ }^{-1}$ and backgrounds equivalent to ${ }^{36} \mathrm{Cl} / \mathrm{Cl}$ around $3 \times 10^{-15}$. A comparison of detector gas mixtures of $\mathrm{Ar}+10 \% \mathrm{CH}_{4}$ and $\mathrm{Ar}+10 \% \mathrm{CF}_{4}$ showed little difference in background levels. Initial experiments have involved hydrological studies at the Nevada Test Site.

\section{ION SOURCE PERFORMANCE}

The GIC Model 846 ion source (Fig. 3) is a 60-sample version of the Model 860 spherical ionizer high-intensity sputter source. Ours was the first to be delivered, and there were initial questions about the expected level of sample cross-talk. Details of the source and the modifications which were required to improve reliability and to suppress memory effects for ${ }^{14} \mathrm{C}$ are given by Proctor et al. (1990).

Further modifications to improve the pumping around the sample were required for ${ }^{36} \mathrm{Cl}$, as the memory problem reappeared due to the volatility of the $\mathrm{AgCl}$ samples. Additional pumping apertures were drilled in the ionizer mounting plate and the immersion lens, the clearance between the Cs beam shaping electrode and the immersion lens was increased, and the Cs shield protecting the cathode insulator was increased in diameter and mounted off the cathode structure rather than

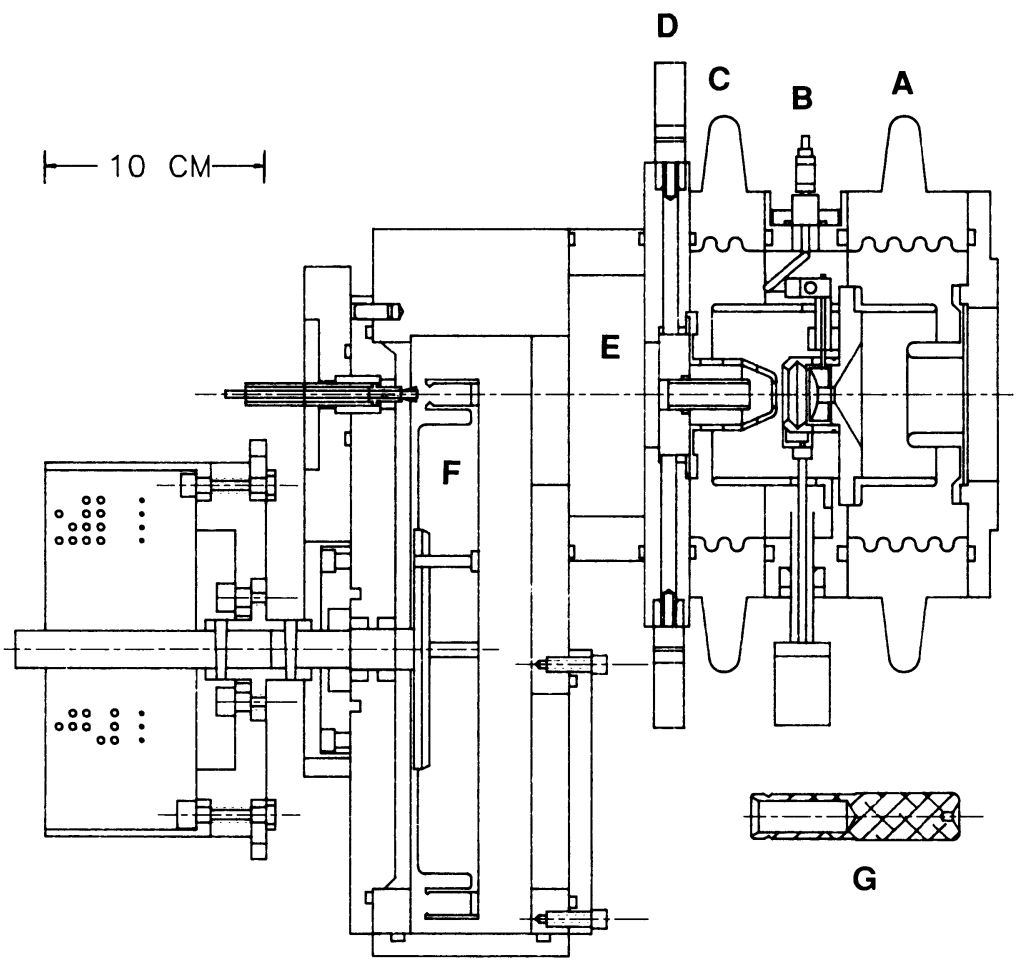

Fig. 3. Major components of the GIC 846 ion source. A-extraction insulator; B-ionizer assembly; C-cathode insulator; D-sample position adjustment; E-gate valve; F-60-sample wheel; G-sample holder (twice scale). The air turbine motor and pneumatic cylinders for sample rotation and insertion are not shown. 
the ionizer mounting plate. Currently, there is no detectable increase in background when a blank is run immediately after a standard with ${ }^{36} \mathrm{Cl} / \mathrm{Cl}=10^{-11}$.

A problem of ionizer poisoning appeared when $\mathrm{AgBr}$ was used as a sample substrate. Source outputs dropped by a factor of 10 over a few hours, and an extremely hard, yellowish deposit formed on the ionizer face. A change in sample holder geometry around the sample hole from the shallow cone shown in Figure 3 to a $1-\mathrm{cm}$ diameter by $2-\mathrm{mm}$ deep, flat-bottomed recess cured the problem, which may have been caused by the implantation in the ionizer surface of sputtered bromine ions.

We have yet to achieve the outputs of $100-200 \mu \mathrm{A}$ of $\mathrm{C}^{-}$observed elsewhere (R. Schneider, personal communication), possibly because of sample overheating. The present shielding of the extraction insulator is still inadequate. The alignment of the sample changer components remains critical, and we have experienced some problems with dropped or sticking samples. However, the currents that the source routinely delivers are high compared to those available in most AMS laboratories, and combined with the high-capacity sample wheel, provide a high sample throughput. The Cs beam spot is less than $1 \mathrm{~mm}$ in diameter and can be aligned to $0.1-0.2 \mathrm{~mm}$, so that small samples are readily handled. We have seen no problems with precision or accuracy which can be unambiguously attributed to the geometry of the source or to the high currents it produces.

Finally, we emphasize again that sample cross-talk is very small. Recently, a graphite blank run immediately after an 800 times modern biomedical sample showed that the memory effect was 2 ppm of the ${ }^{14} \mathrm{C}$ count rate from the "hot" sample after one minute and was visibly dropping. Also, incidents where 20-30 k times modern samples were inadvertently sputtered for short periods have shown that background levels are back to normal within minutes. Although it is clearly essential to separate sample preparation areas for biomedical and archaeological/geoscience applications, use of a common ion source does appear practical.

\section{ACKNOWLEDGMENTS}

Support from programmatic and Institutional Research and Development funding of the Lawrence Livermore Laboratory and from the Regents of the University of California is gratefully acknowledged. We thank Peter Kubik and Kuni Nishiizumi for providing ${ }^{36} \mathrm{Cl}$ and ${ }^{10} \mathrm{Be}$ standards and for other assistance. This work was performed under the auspices of the USDOE by the Lawrence Livermore National Laboratory under contract W-7405-Eng-48.

\section{REFERENCES}

Davis, J. C., Proctor, I. D., Southon, J. R., Caffee, M. W., Heikkinen, D. W., Roberts, M. W., Moore, T. L., Turteltaub, K. W., Nelson, D. E., Loyd, D. H. and Vogel, J. S. 1990 LLNL/UC AMS facility and research program. In Yiou, F. and Raisbeck, G. M., eds., Proceedings of the 5th International Conference on Accelerator Mass Spectrometry. Nuclear Instruments and Methods B52(3,4): 269-272.

Fifield, L. K., Ophel, T. R., Allan, G. L., Bird, J. R. and Davie, R. F. 1990 AMS at the Australian National University's 14UD accelerator: experiences and developments. In Yiou, F. and Raisbeck, G. M., eds., Proceedings of the 5th International Conference on Accelerator Mass Spectrometry. Nuclear Instruments and Methods B52(3,4): 233-237.
Proctor, I. D., Southon, J. R., Roberts, M. L., Davis, J. C., Heikkinen, D. W., Moore, T. L., Garibaldi, J. L. and Zimmerman, T. A. 1990 The LLNL ion source - past, present and future. In Yiou, F. and Raisbeck, G. M., eds., Proceedings of the 5th International Conference on Accelerator Mass Spectrometry. Nuclear Instruments and Methods B52(3,4): 334-337.

Vogel, J. S. 1992 Rapid production of graphite without contamination for biomedical AMS. Radiocarbon, this issue.

Vogel, J. S., Nelson, D. E. and Southon, J. R. $1987{ }^{14} \mathrm{C}$ backgrounds in an accelerator mass spectrometry system. Radiocarbon 29(3): 323-333. 